\title{
Nutritional investigation of phagotrophic Protozoa under axenic conditions
}

\author{
M. R. DRoOP \\ Scottish Marine Biological Association; Oban, Scotland
}

KURZFASSUNG: Untersuchungen über die Ernährung phagotropher Protozoen unter axenischen Bedingungen. Eine keimfreie Kultur mit definierten Nährlösungen ist das entscheidende Verfahren, die Nahrungsansprüche eines Organismus qualitativ und quantitativ festzustellen. Bislang ist die Methode nur bei wenigen Meeres-Protozoen angewandt worden. Der phagotrophe Dinoflagellat Oxyrrbis marina, ein Bewohner des Felslitorals, ist in dieser Hinsicht ausführlicher als andere Meeresorganismen untersucht worden. Folgende organische Verbindungen, für die zum Teil auch quantitative Werte ermittelt werden konnten, haben sich als essentiell für die Ernährung von O. marina erwiesen (Bezug auf $10^{8}$ Zellen): Essigsäure oder Äthanol $1 \mathrm{~g}$; Valin, Alanin oder L-Prolin $150 \mathrm{mg}$; Biotin; Thiamin $3 \mu \mathrm{g}$, Vitamin $\mathrm{B}_{12} 30 \mathrm{ng}$, Ubichinon oder Plastochinon $50 \mu \mathrm{g}$; Cholesterin oder gewisse andere Steroide.

\section{INTRODUCTION}

The number of phagotrophic organisms that have been cultivated in the absence of all other organisms in completely defined media is still rather small, especially in the marine field. Yet this approach affords the most direct and most critical means of establishing absolute nutritional requirements, both from a qualitative and quantitative point of view. The interpretations, ecological or otherwise, of findings from axenic cultures must necessarily be open to debate, but this does not affect the primary function, and indeed success, of the axenic method, namely of defining nutritional needs in chemical terms.

Cultivation of Protozoa and small invertebrates, at least in my hands, follows a set pattern with the following well marked phases:

(1) Monoxenic cultivation with an obligately phototrophic alga as food source.

(2) Axenic cultivation. Obviously this is only possible by finding a substitute for the living food alga.

(3) Identification of the water-soluble nutrient requirements.

(4) Identification of the fat-soluble nutrient requirements.

Oxyrrbis marina can claim to be nutritionally one of the better known phagotrophic Protozoa. BARKer (1935) made the earliest nutritional studies on it but never attempted axenic cultures. It is a supra-littoral organism, an apochlorotic dinoflagellate 
of voracious habit, to all intents and purposes an animal, though with many plantlike nutritional features, as it was later to prove. I shall recount my work with this organism to illustrate some of the features of the germ-free method.

\section{ISOLATION}

I should perhaps stress at the outset that the organism should be carefully selected. It has to be tough enough to withstand some pretty severe handling; hence narrow tolerance limits are a disadvantage, and, to begin with, littoral species are to be preferred to pelagic ones e. g., Tigriopus rather than Calanus, Brachionus rather than Synchaeta, Oxyrrbis rather than Noctiluca.

Isolation and purification are usually easily effected by manipulative or antibiotic methods or by a combination of the two, and, in the case of metazoans, working with eggs or larval stages rather than adults. Oxyrrhis, being small and motile enough to be clean and yet not too small to handle, was originally purified by Pringsheim's washing method (Droop 1953). It grew quite happily on any one of quite a variety of pure cultures of algae (Droop 1966). The advantage of using an obligate phototroph as food at this stage is that it greatly simplifies the passage to the next phase. The culture has merely to be incubated in the dark in a suitable medium to eliminate the algal food. I used Nannocbloris oculata for Oxyrrbis and also for Bodo; Bracbiomonas submarina for Heteramoeba, Philodina and Brachionus; and Cricosphaera elongata for Noctiluca miliaris.

\section{AXENIC CULTURES}

Achievement of axenic cultures depends on finding a complete substitute for the living alga. This is the most crucial step of the whole project, for once the food has been narrowed to non-living material there is, at least in principle, the possibility of defining it in chemical terms. The difficulty of this step arises from the fact that a phagotroph is not dependent on dissolved nutrients, so that the range of synthetic disabilities that can be survived is greatly enhanced. One must be prepared to find requirements for lipids and other intermediates too labile to exist for long outside the protection of a living cell.

It would be tedious to recount the months of trials and failures with supplements ranging from egg yolk to extracts of corpus luteum. The medium for the first successful axenic cultures of Oxyrrbis contained a little neutralized lemon juice as an essential ingredient. The juice was later replaced by an ethanol solution of rind lipids. Ethanol solutions emulsify when added to culture media, and are the most satisfactory way of administering lipids and the one I normally adopt. The inclusion of lemon juice, enabled vaN WAGTENDONK (1955) to cultivate Paramaecium aurelia axenically. The lipid requirements of Oxyrrhis, however, proved to be different from those of P. aurelia. 


\section{WATER-SOLUBLE NUTRIENT REQUIREMENTS}

The stage was now set for working out the nutritional requirements. Nutrients may conveniently be grouped according to the scale of requirement: (1) Carbon source; (2) nitrogen source; (3) minor nutrients; (4) trace metals; (5) growth factors; (a) water-soluble, (b) lipid.

The requirement for carbon is very high, and unless the absorbtive surface area of the organism is relatively very large it simply cannot obtain sufficient for its needs from solution, but must be given its carbon in packaged form (e. g. emulsified fats, starch, etc.). Bracbionus, for example, needs to be given milk fats or Arachis oil. The culture medium for Oxyrrbis, on the other hand, except for the lemon rind lipids, was composed entirely of water-solubles: natural sea water, water-soluble liver and soil extracts and casein hydrolysate.

It was a relatively simple, though lengthy, proceeding to sort out the essential organic ingredients of this medium (Droop 1958, 1959, Droop et al. 1959). Thus, acetic acid or ethanol as $\mathrm{C}$ source, valine, proline or alanine (not $\mathrm{NO}_{3}{ }^{-}$nor $\mathrm{NH}_{4}{ }^{+}$) as $\mathrm{N}$ source, and vitamin $\mathrm{B}_{12}$ (with "Ochromonas specificity"), thiamine (thiazole), biotin and proline as growth factors. The trace metal requirements were not ascertained; trace metals were included in the chelated and buffered artificial sea water base. So we see, except for the proline and unknown lipid requirements, a fairly conventional nutritional pattern typical of many lower algae, especially "acetate flagellates". The simplicity of its nutrition obviously accounts for my success with this organism.

\section{LIPID REQUIREMENTS}

None of the previously reported lipid growth factors, vitamins $\mathrm{A}, \mathrm{K}$, and $\mathrm{E}$, lecethin, linoleic acid or sterols could replace the lemon rind extract, so it was necessary to try and get some idea of the nature of the active material by chemical separation and bio-assays. The activity proved stable to autoclaving, but labile to light and saponification. Chromatography on alumina failed to separate the activity from a plethora of coloured and fluorescent material. However, grass extract, which also contained the essential factors, was amenable to chromatography and it was possible to separate the activity from all coloured fractions. The U. V. absorption spectrum of the active fraction showed a strong peak at $272 \mathrm{~mm}$, absent in adjacent fractions, which led us correctly to suspect ubiquinone (Droop \& Doyle 1966). Ubiquinone was able to replace the lemon rind lipids, and Oxyrrbis responded quantitatively to minute amounts of it.

Ubiquinone was the most vital lipid requirement. Once this was satisfied it became possible to demonstrate another, less vital one, in the form of a sterol.

\section{SPECIFICITY OF THE QUINONE AND STEROL REQUIREMENTS}

To show how far one can take this kind of nutritional work I shall report shortly on some aspects of the specificities of these lipid requirements, without however dis- 
cussing the biochemical significance of the findings. The full account is to be published elsewhere.

Quinones in electron transport are either naphthoquinones (vitamins $\mathrm{K}$ ) or benzoquinones, with either a saturated (phytyl) or unsaturated (polyprenyl) side chain. These are set out in Figure 1. Growth factor activity for Oxyrrbis is confined to the two compounds within the box, namely ubiquinone and plastoquinone. The requirement appears to be specifically for a fully-formed substituted benzoquinone with an unsaturated side chain. Neither vitamin $\mathrm{E}$ nor any of the $\mathrm{K}$ vitamins were active, nor were the two parts of the ubiquinone molecule together but uncombined.<smiles>CC(C)=CCCC(C)(C)CCO</smiles>

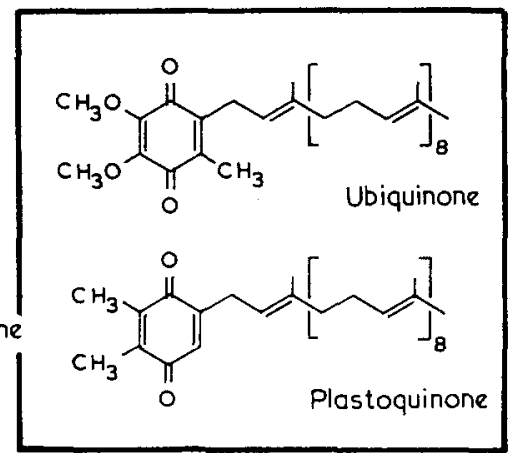

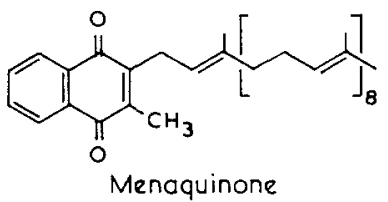<smiles>CC(=CCC1=C(C)C(=O)c2ccccc2C1=O)CCCC(C)C</smiles>

Fig 1: Some biologically important quinones

The unsaturated isoprenoid side chain of ubiquinone varies in length according to the organism of origin; normal mammalian ubiquinone has 9 or 10 prenyl residues. Interestingly, activity for Oxyrrbis was confined to members of the homologous series having a chain length of six or more residues (Table 1 ).

Table 1

Effect of chain length on the activity of ubiquinone homologues for Oxyrrhis marina. Chain length as number of prenyl $\left[-\left(\mathrm{CH}_{2}\right)_{2} \cdot \mathrm{CH}_{2}: \mathrm{CH}_{2} \cdot \mathrm{CH}_{3} \cdot \mathrm{CH}_{2}-\right]$ residues. The relative activity of the quinone-free controls in these assays ranged from $3 \%$ to $9 \%$

\begin{tabular}{|llllllllllrl|}
\hline Chain length (prenyl residues) & 0 & 1 & 2 & 3 & 4 & 5 & 6 & 7 & 8 & 9 & 10 \\
\hline Relative activity $(\%)$ & 6 & 8 & 5 & 8 & 7 & 18 & 100 & 111 & 91 & 120 & 80 \\
\hline
\end{tabular}


Incidentally, no interference with the double bonds of the side chain was to be tolerated. Evidently a degree of rigidity is needed in this very long chain.

Biosynthesis of ubiquinone is thought to proceed by attachment of the long chain alcohol to $p$-hydroxybenzoic acid, followed by stepwise substitutions in the ring. If this hypothesis is correct the synthetic lesion in Oxyrrbis must be at a very late stage, for it was found just permissible to substitute one of the methoxy radicles on the quinone ring by another radicle, whereas substitution of both methoxy radicles completely destroyed activity. This is an extremely specific requirement; it is also unique,

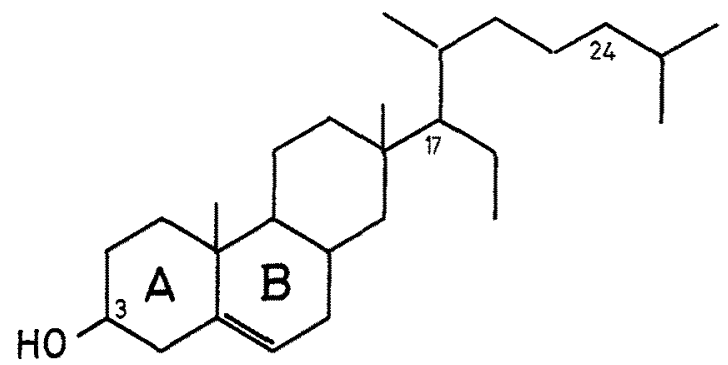

Fig. 2: Cholesterol

The specificity of the sterol requirement was similarly ascertained, although the experimental results were seldom quite as clear-cut as the quinone ones, and the requirement is possibly not an absolute one. The cholesterol molecule is shown in Figure 2. I found that the side chain at position 17 must include the branched $-\mathrm{CH}_{2}\left(\mathrm{CH}_{3}\right)_{2}$ ending, but the presence or absence of a branch at 24 is not important. The degree of saturation in ring $B$ is apparently immaterial, but this ring must not be opened as in the $\mathrm{D}$ vitamins. Substitution or removal of the hydroxyl at position 3 in ring $\mathrm{A}$ is permitted. Thus, many of the common sterols could replace cholesterol: sitosterol, stigmasterol, ergosterol, 7-dehydrocholesterol, cholestanol, cholestane or cholestenone; whereas such compounds as cholenic acid, androstendiol, pregnenolone or vitamins $\mathrm{D}_{2}$ and $\mathrm{D}_{3}$ could not. This pattern is rather similar to that shown by the parasitic Trichomonas columbae (LwOFF 1955). Both Paramoecium aurelia and Labyrintbula are rather more specific in their sterol requirements (see VAN WAGTENDONK 1955).

\section{CONCLUSIONS}

The details or nutritional requirements of phagotrophic organisms are of course of greatest interest from the point of view of comparative nutrition, but they may also afford a clue to the feeding habits of the subject. The requirements of Oxyrrbis are relatively simple, however, hence the wide choice of suitable food organisms (Droop 1966). Even the quinone requirement imposes small restriction, for the natural diet is largely composed of photosynthetic species presumably rich in plastoquinone. 
As a final remark, one should perhaps emphasize that a list of absolute requirements gleaned from axenic cultures is obviously a minimal one, taking no account of the digestive powers of the subject and the fact that the natural food is packaged and not subject to permeability barriers. One can never say of one's list "these compounds and no others must be among those supplied by the food organism".

\section{SUMMARY}

The organic requirements of the dinoflagellate Oxyrrbis marina in amounts (where known) per $10^{8}$ cells are: acetic acid or ethanol $1.0 \mathrm{~g}$; valine, alanine or L-proline $150 \mathrm{mg}$; L-proline; biotin; thiamine $3.0 \mu \mathrm{g}$; vitamin $\mathrm{B}_{12} 30 \mathrm{ng}$; ubiquinone or plastoquinone $50 \mu \mathrm{g}$; and a sterol.

Acknowledgements. The work on quinone specificity was carried out in collaboration with Dr. J. F. PENNock (Biochemistry Department, University of Liverpool) who prepared many of the quinones. Others were generously provided by Professor O. Ister and Dr. O. Wiss (Hoffmann-La Roche \& Co., Basle). The observations on Brachionus were made by my colleague Mr. M. Scot'T.

\section{LITERATURE CITED}

Barker, H. A., 1935. The culture and physiology of marine dinoflagellates. Arch. Mikrobiol. 6, $157-181$.

Droop, M. R., 1953. Phagotrophy in Oxyrrhis marina. Nature, Lond. 172, 250.

- 1958. Requirement for thiamine among some marine and supra-littoral protista. $J$. mar. biol. Ass. U. K. 37, 323-329.

- 1959. Water-soluble factors in the nutrition of Oxyrhis marina. J. mar. biol. Ass. $U . K$. $38,605-620$.

- 1966. The role of algae in the nutrition of Heteramoeba clara Droop with notes on Oxyrrbis marina Dujardin and Pbilodina roseola Ehrenberg. In: Some Contemporary studies in marine science. Ed. by H. Barnes. Allen \& Unwin, London, 269-282.

- \& DOYLE, J., 1966. Ubiquinone as a protozoan growth factor. Nature, Lond. 212, $1474-1475$.

- Mclaughlin, J. J. A., Pintiner, I. J. \& Provasoli, L., 1959. Specificity of some protophytes toward vitamin $B_{12}$ like compounds. In: Preprints of abstracts of papers ... International Oceanographic Congress, New York 1959. Ed. by M. Sears. Am. Ass. for the Advmt of Sci., Washington, D. C., 916-918.

LwOFF, M., 1955. The nutrition of parasitic flagellates (Trypanosomidae, Trichomonadinae). In: Biochemistry and physiology of protozoa. Vol. 1. Ed. by A. Lwoff. Academic Press, New York.

WAGTENDONK, W. J. VAN, 1955. The nutrition of ciliates. In: Biochemistry and physiology of protozoa. Vol. 2. Ed. by S. Hutner \& A. Lwoff. Academic Press, New York, 57-90.

Author's address: Dr. M. R. Droop

Scottish Marine Biological Association

P.O. Box 3

Oban, Scotland 